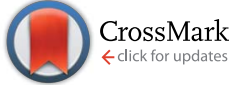

Cite this: RSC Adv., 2017, 7, 14660

Received 20th January 2017

Accepted 15th February 2017

DOI: $10.1039 / c 7 r a 00844 a$

rsc.li/rsc-advances

\section{Preparation of mechanically stable triple-layer interference broadband antireflective coatings with self-cleaning property by sol-gel technique $\uparrow$}

\author{
Yuanyang Li, ${ }^{a}$ Ke Yang, ${ }^{b}$ Bibo Xia, ${ }^{a}$ Bowen Yang, ${ }^{a}$ Lianghong Yan, ${ }^{b}$ Meiying $\mathrm{He}{ }^{a}$ \\ Hongwei Yan*b and Bo Jiang*a
}

Antireflective coatings usually suffer from poor functional durability during outdoor service. The incorporation of additional properties, such as broadband antireflection, self-cleaning and mechanical stability, is of great importance. In the current work, we synthesized broadband AR coatings via the design concept of triple-layer interference coating. $\mathrm{SiO}_{2}-\mathrm{TiO}_{2}, \mathrm{TiO}_{2}$ and nanoporous $\mathrm{TiO}_{2}-\mathrm{SiO}_{2}$ composite thin films were employed as bottom, middle and top layers. Substrates (BK-7 glass) coated with the triple-layer films attained consistent high transmittances at 500-700 nm and the average transmittance at that region was $99.4 \%$. The triple-layer films exhibited an outstanding superhydrophilic property with water contact angle of $2^{\circ}$ in $0.5 \mathrm{~s}$, and the superhydrophilicity could last for 30 days in the absence of UV illumination. These triple-layer coatings also showed a good ability to decompose organic substances under UV irradiation. The synergistic effect between superhydrophilicity and photocatalysis provides the films with self-cleaning effect. Meanwhile, the abrasion resistance test of the triple-layer films indicated favorable robustness and good adhesion of the films to substrates. This multifunctional film can have potential applications in various areas, like solar cell panels, green houses and architectural glasses.

\section{Introduction}

Antireflective (AR) coatings have been widely used in optical devices and energy-related applications, such as solar cells, windscreens and high power lasers, to suppress the undesired interfacial Fresnel reflections..$^{1-5}$ Conventional single-layer quarter-wave AR coatings, which only work over a narrow band of wavelengths, are seriously limited in application. In many situations such as solar systems and display systems, a broad low-reflection region is required. Driven by the demand for AR coatings with better AR characteristics, a variety of broadband AR coating designs have been proposed or demonstrated.

Some encouraging broadband AR coating technologies are based on subwavelength structures (SWSs) inspired by moth eyes. As the structural features of the hexagonally arranged pattern of conelike protuberances are below the diffraction limit, the surface appears to have a continuous refractive index gradient between air and substrate that practically removes the

${ }^{a}$ Key Laboratory of Green Chemistry \& Technology, College of Chemistry, Sichuan University, Chengdu, 610064, China.E-mail: jiangbo@scu.edu.cn

${ }^{b}$ Research Center of Laser Fusion, China Academy of Engineering Physics, Mianyang, 621900, China.E-mail: hwyan@163.com

$\dagger$ Electronic supplementary information (ESI) available. See DOI: 10.1039/c7ra00844a optical interface. SWSs can be realized using various technologies such as a "top-down" patterning including self-assembly of nanoparticles, ${ }^{6,7}$ nanoimprint lithography, ${ }^{8}$ etching process ${ }^{9,10}$ or "bottom-up" growth of tapered nanorods. ${ }^{11}$ All of these SWSs coatings were reported to strongly suppress reflectance over a very broad spectral region.

An alternative way of reducing broadband reflectance is to gradually reduce the refractive index of the film from the refractive index of the substrate $\left(n_{\mathrm{s}}\right)$ to the refractive index of air $\left(n_{\text {air }}\right)$. This graded refractive index (GRIN) structure can be realized with quintic/modified quintic profiles ${ }^{12,13}$ or multiplediscrete-layer design. ${ }^{\mathbf{1 4 1 5}}$ AR coatings with these refractive index profiles are able to achieve a better broadband AR property. However, optical materials with very low refractive indices that closely match the refractive index of air are needed. Yet such low-refractive-index materials generally have a low packing density, which affects the mechanical strength of the AR coatings and thus raises durability issues especially in outdoor use. ${ }^{16,17}$

Double/multiple interference films can also realize broadband AR function by destructive interference of light reflected at different interfaces. Compared to the complex fabrication processes of aforementioned bionic broadband AR thin films or graded-refractive-index films, however, this method is simpler. As to double-layer interference films, ${ }^{18-20}$ the refractive index of the top-layer needs to be sufficient low, thus film material is 
always limited to the one with low refractive index, such as $\mathrm{SiO}_{2}$. In contrast, triple-layer interference films with quarter-halfquarter wavelength in optical thickness (i.e. $\lambda / 4-\lambda / 2-\lambda / 4$ ) may be a better choice, as they can provide consistent high transmittances in a broad region and do not need material with very low refractive index. ${ }^{21-23}$ The design concept of $\lambda / 4-\lambda / 2-\lambda / 4$ triple-layer interference films was first described and realized by Lockhart and King. ${ }^{21}$ The obtained triple-layer AR coating afforded the substrate a constant low-reflectance over the entire visible region. Our group ${ }^{23}$ optimized Lockhart's triple-layer AR coating by investigating the effect of refractive indices of three layers on broadband AR property. The glass coated with the resultant $\mathrm{SiO}_{2} / \mathrm{TiO}_{2} / \mathrm{SiO}_{2}-\mathrm{TiO}_{2}$ triple-layer coating achieved an average transmittance as high as $98.4 \%$ at visible region. However, films' self-cleaning capacity, which is crucial for outdoor service, was not investigated in the study.

In practical application, however, AR coatings with only antireflection capacity usually suffer from optical function loss due to the accumulation of contaminants and the poor mechanical robustness. Titania $\left(\mathrm{TiO}_{2}\right)$ was widely applied to improve the durability and mechanical robustness of thin films ${ }^{24-26}$ because of its interesting properties including photoinduced superhydrophilicity, photocatalytic activity, antibacterial function and high hardness. However, incorporating $\mathrm{TiO}_{2}$ into AR coatings poses a major challenge because of its high refractive index $(n>$ 2.0). ${ }^{27}$ And thus, when it is applied as AR coatings, the percentage of $\mathrm{TiO}_{2}$ must be kept low. However, the low $\mathrm{TiO}_{2}$ content is unfavorable for the self-cleaning property. Another problem is that the photocatalysis activity and photo-induced hydrophilicity will be affected in the absence of UV exposure, such as in rainy or cloudy days. So a film, which can have a better efficiency of self-cleaning property even at low intensity of UV irradiation, is highly desired. As previously reported, films with porous structure tend to maintain superhydrophilicity for a long time in the absence of UV light. ${ }^{26,28,29}$ And the porous structure is also beneficial to films' photocatalytic activity. ${ }^{30,31}$ However, on the other hand, the high porosity can have an adverse impact on mechanical stability. ${ }^{\mathbf{1 6 , 1 7}}$ In summary, fabrication of films with these integrated properties (i.e. broadband AR, photocatalytic activity, durable superhydrophilicity and mechanical stability) is a complicated challenge that demands a detailed investigation to achieve a balance between them. Recently, $\mathrm{SiO}_{2}-\mathrm{TiO}_{2}$ hybrid films have been increasing studied due to their significant potential in realizing such multifunctionality. ${ }^{15,26,32}$

Huang et al. ${ }^{15}$ fabricated $\mathrm{TiO}_{2}-\mathrm{SiO}_{2}$ stack coatings with graded refractive index (GRIN) structure. The broadband AR property was achieved over the solar spectrum with an increase of solar transmittance by $7.80 \%$ and maximum transmittance of $99.16 \%$ at $550 \mathrm{~nm}$. Nevertheless, the coating (WCA: $25-80^{\circ}$ ) was not superhydrophilic, which is favorable for self-cleaning and antifogging functions. He's group ${ }^{26}$ synthesized $\mathrm{SiO}_{2} \& \mathrm{TiO}_{2}$ double-shell hollow nanospheres (DSHNs) and DSHNs-based multifunctional AR thin films. Substrates with DSHN thin films attained transmittance as high as $99.4 \%$ and average transmittance up to $98.5 \%$ in the visible region. This $\mathrm{SiO}_{2} \& \mathrm{TiO}_{2}$ film exhibited intrinsic superhydrophilicity, anti-fogging and high photocatalytic activity. Unfortunately, the film coated substrate achieved maximum transmittance at a given wavelength other than at a broad region. The research of multifunctional $\mathrm{TiO}_{2}-\mathrm{SiO}_{2}$ coatings usually either focused on the broadband AR property but ignored the durability of the coatings, or did not attach importance to broadband AR property and the transmittance curves of the obtained films were just the same as that of the single-layer quarter-wave AR coatings. Few works took all these properties into account and achieved a balance between them.

In the current work, we designed a $\lambda / 4-\lambda / 2-\lambda / 4$ triple-layer broadband AR coating. Compared to the most of the broadband AR coatings' preparation methods which need a material with a very low refractive index, our design only requires an index of 1.41 as top layer (the layer requires a lowest refractive index among the three layers, Details in 3.1), so it is possible to introduce a certain amount of $\mathrm{TiO}_{2}$ into the film. Actually, we adopted nanoporous $\mathrm{SiO}_{2}-\mathrm{TiO}_{2}$ composite film as top layer on the purpose of obtaining a natural superhydrophilicity as well as enhancing the photocatalysis activity. However, considering its negative effect to mechanical strength, the porosity was limited. Thus, a multifunctional thin film with the desired characteristics (i.e. broadband antireflective, self-cleaning and mechanical stability) can be realized.

The $\lambda / 4-\lambda / 2-\lambda / 4$ triple-layer films were fabricated by a simple sol-gel dip-coating process. Films' refractive index and thickness of each layer were optimized with the aid of thin film design software (TFCalc ${ }^{\mathrm{TM}}$ ). Substrates (BK-7 glass) coated with the triple-layer films attained consistent high transmittances at 500-700 $\mathrm{nm}$ and the average transmittance at that region was $99.4 \%$. At the entire visible region, the average transmittance was $98.7 \%$. This triple-layer film showed instinct superhydrophilicity which can last for a month and high photocatalytic activity. Meanwhile, the abrasion-resistance tests showed the favorable robustness of the triple-layer films. Thus, the triple-layer interference films with multifunctional properties of broadband antireflection, durable superhydrophilicity, photocatalysis and mechanical stability were successfully realized and the multifunctional films can have potential applications in various areas, like solar cell panels, green houses and architectural glasses.

\section{Experimental section}

\section{Materials}

Tetraethylorthoxylsilicane (TEOS, 98\%) and F127 Pluronic $\left(\mathrm{EO}_{106}-\mathrm{PO}_{70}-\mathrm{EO}_{106}, M_{\mathrm{w}}=12600 \mathrm{~g} \mathrm{~mol}^{-1}\right)$ were purchased from Sigma-Aldrich. Titanium n-butoxide (n-Buti, 99\%) was purchased from Acros. Hexadecyltrimethoxysilane (HDTMS, 85\%) was purchased from Aladdin. Ethanol (EtOH) and concentrated hydrochloric acid $(\mathrm{HCl}, 37 \%)$ were purchased from Kelong Chemical Reagents Factory. The water was deionized. All chemicals were used without further purification.

\section{Preparation of acid-catalyzed $\mathrm{SiO}_{2}$ sol}

Tetraethylorthoxylsilicane (104 g) was mixed with anhydrous ethanol (860 g) and water (36 g) that contained concentrated 
hydrochloric acid $(0.2 \mathrm{~g})$. The final molar ratio of TEOS : EtOH : $\mathrm{H}_{2} \mathrm{O}: \mathrm{HCl}$ was $1: 37.5: 4: 0.004$ and the concentration of equivalent $\mathrm{SiO}_{2}$ was $3 \mathrm{wt} \%$ (assuming that $1 \mathrm{~mol}$ of TEOS gives $1 \mathrm{~mol}$ of $\mathrm{SiO}_{2}$ ). The solution was stirred in a closed glass container at $30^{\circ} \mathrm{C}$ for $2 \mathrm{~h}$, and then aged at room temperature for 7 days.

\section{Preparation of acid-catalyzed $\mathrm{TiO}_{2}$ sol}

$\mathrm{TiO}_{2}$ sol was prepared by mixing EtOH, $\mathrm{H}_{2} \mathrm{O}$ and $\mathrm{HCl}$ first, and then dropwise adding $n$-Buti under stirring. The molar ratio of $n$-Buti : $\mathrm{H}_{2} \mathrm{O}: \mathrm{C}_{2} \mathrm{H}_{5} \mathrm{OH}: \mathrm{HCl}$ was $1: 3.55: 49.75: 0.22$ and the final concentration of $\mathrm{TiO}_{2}$ was $3 \%$ by weight (assuming that $1 \mathrm{~mol}$ of $n$-Buti gives $1 \mathrm{~mol}$ of $\mathrm{TiO}_{2}$ ). The solution was stirred in a closed glass container at $30^{\circ} \mathrm{C}$ for $2 \mathrm{~h}$, and then aged at room temperature for 7 days.

\section{Preparation of template-based $\mathrm{SiO}_{2}-\mathrm{TiO}_{2}$ composite sols}

The aged $\mathrm{SiO}_{2}$ sol and $\mathrm{TiO}_{2}$ sol were mixed with various weight ratios. The proportions of $\mathrm{TiO}_{2}$ sol to composite sol were $0 \%$, $10 \%, 20 \%, 30 \%, 40 \%, 50 \%, 60 \%$. The mixed sols were aged at $30{ }^{\circ} \mathrm{C}$ for 7 days. And then the template F127 was added into the composite sols. The weight percent of F127 to composite sol varied from $0 \%$ to $6 \%$.

\section{Films preparation}

BK-7 substrates $(\Phi=35 \mathrm{~mm}, d=3 \mathrm{~mm})$ were cleaned by ultrasonication in acetone for $10 \mathrm{~min}$ and wiped carefully before dip-coating. The sols were deposited on BK-7 substrates by dipcoating under ambient condition of $30 \% \mathrm{RH}$ (relative humidity) and $30{ }^{\circ} \mathrm{C}$. The thickness of the film was optimized by varying dip-coating speeds (withdraw rates). $\mathrm{SiO}_{2}-\mathrm{TiO}_{2}, \mathrm{TiO}_{2}$, and nanoporous $\mathrm{TiO}_{2}-\mathrm{SiO}_{2}$ composite thin films were employed as bottom, middle and top layer, respectively. The corresponding sols were deposited on a BK-7 substrate sequentially with an interval of 2 minutes to ensure complete evaporation of solvent. The withdraw rates for bottom, middle and top layer were about $175 \mathrm{~mm} \mathrm{~min}^{-1}, 500 \mathrm{~mm} \mathrm{~min}^{-1}$ and $160 \mathrm{~mm} \mathrm{~min}^{-1}$, respectively. The as-deposited triple-layer films were pre-heated at $100{ }^{\circ} \mathrm{C}$ for $1 \mathrm{~h}$, and then annealed at $400{ }^{\circ} \mathrm{C}$ for $2 \mathrm{~h}$ to completely remove the organic species and ensure crystallization of $\mathrm{TiO}_{2}$. Apart from the above-described thin film samples, $\mathrm{TiO}_{2}$ powder samples were also prepared by the same procedure as the thin films; $\mathrm{TiO}_{2}$ sol was firstly dried at $100{ }^{\circ} \mathrm{C}$ in air in order to obtain a gel, and then annealed at $400{ }^{\circ} \mathrm{C}$ for $2 \mathrm{~h}$, and eventually grounded by an agate pestle and mortar to obtain $\mathrm{TiO}_{2}$ power.

\section{Characterizations and measurements}

X-ray diffractometer (XRD, Philips X'PertMRD, Netherlands) was employed to study the crystal structure of the powder samples with a scanning rate of $5^{\circ} \mathrm{min}^{-1}$ from $20^{\circ}$ to $80^{\circ}$, using $\mathrm{Cu} \mathrm{K} \alpha$ radiation. Fourier transform infrared (FTIR) spectra of the films were analyzed by FTIR (Brubler Tensor 27) in transmission mode. The samples were deposited on $\mathrm{KBr}$ salt tablets via sol-gel dip-coating method. To determine particle size and distribution, the $\mathrm{SiO}_{2}$ and $\mathrm{TiO}_{2}$ sols were analyzed by dynamic light scattering (DLS, Malvern Nano-ZS, wavelength of 632.8 $\mathrm{nm}$ ) at $25{ }^{\circ} \mathrm{C}$. Water contact angles were measured with a Krüss DSA100 (Germany) instrument using deionized water as the probe liquid. The angle precision is $\pm 0.1^{\circ}$. The measurement was carried out on five different areas of the sample surface with water droplets of $3 \mu \mathrm{L}$. The process of the water droplet contacting the samples was recorded by a video, and the videos were analyzed with DSA (drop shape analysis) software. This software can measure the transient contact angle during the spreading of liquid on samples' surface. For examination of antifogging property, a control BK-7 glass and a BK-7 glass with triple-layer film were cooled at $c a .0{ }^{\circ} \mathrm{C}$ for $2 \mathrm{~h}$ in a refrigerator and then exposed to laboratory air. The experimental transmittance spectrum was measured with an UV-vis spectrophotometer (Mapada, UV-3100PC) over range of 400-800 nm. The refractive indices $n$ and thicknesses of AR coatings were determined by an ellipsometry (SENTECH SE850 UV) using a He-Ne laser as the light source $(\lambda=632.8 \mathrm{~nm})$. The surface topography of the coatings was studied with atomic force microscopy (AFM, SEIKO SPA-400). The surface root-mean-square (RMS) roughness values were obtained from the analysis of atomic force microscopy (AFM) images. Cross-sections of the AR coatings were investigated by scanning electrons microscope (SEM, JSM$5900 \mathrm{LV}$ ). The mechanical durability of the triple-layer coating was assessed by an abrasion-resistance machine (DZ-8103, Dongguan City Dazhong Instrument CO, LTD.), on which a standard normal stress $25 \mathrm{kPa}$ was applied with rotational shear (100 rpm for $0.5 \mathrm{~h}$ ). The mechanical damages of the films were determined by the changes of transmittances before and after the abrasion tests.

The photocatalytic self-cleaning property of prepared thin films was evaluated by investigating their ability to decompose alkyl under UV irradiation. The films were placed in a desiccator containing a small beaker of HDTMS for a period of $48 \mathrm{~h}$ at $50{ }^{\circ} \mathrm{C}$. The vaporized silane reacted with the hydroxyls on the surface of the $\mathrm{TiO}_{2}$ and $\mathrm{SiO}_{2}$, and formed a monolayer on the films. After modification by silane monolayer, the surfaces of the films were hydrophobic. The photocatalytic activities were evaluated by measuring the water contact angle of the films at intervals during UV illumination. UV irradiation was provided by a UV reactor with high pressure mercury lamp (300 W) as light source and circulating-water to remove the effect of heat.

\section{Results and discussion}

\section{Computer-aid design of triple-layer broadband AR coatings}

In this work, $\lambda / 4-\lambda / 2-\lambda / 4$ triple-layer AR coatings were designed with the aid of thin film design software TFCalc ${ }^{\mathrm{TM}}$. Some typical triple-layer films modeled by the software were listed in Table 1 and the transmittance spectra of some modeled films were shown in Fig. 1. The central wavelength was settled at $550 \mathrm{~nm}$. As shown in Table 1, the lower refractive index of top layer, the better AR performance of the triple-layer film (samples $\mathrm{C} 1$ and C9). Since nanoporous $\mathrm{TiO}_{2}-\mathrm{SiO}_{2}$ film was employed as top layer, the refractive index of the top layer can be decreased by increasing the porosity. Taking into account the content of $\mathrm{TiO}_{2}$ and films' mechanical strength, we finally adopted 1.42 to be 
Table 1 The parameters of the modeled $\lambda / 4-\lambda / 2-\lambda / 4$ triple-layer AR coatings on BK7 glass (refractive index $n$ and thickness $d$, the central wavelength for these coatings is $550 \mathrm{~nm}$ )

\begin{tabular}{|c|c|c|c|c|c|c|c|}
\hline Sample number & $n_{1}$ & $d_{1}(\mathrm{~nm})$ & $n_{2}$ & $d_{2}(\mathrm{~nm})$ & $n_{3}$ & $d_{3}(\mathrm{~nm})$ & $T_{\text {avg }}(\%, 400-800 \mathrm{~nm})$ \\
\hline $\mathrm{C} 2$ & 1.69 & 81 & 2.00 & 138 & 1.42 & 97 & 98.94 \\
\hline C3 & 1.75 & 79 & 2.14 & 129 & 1.42 & 97 & 98.92 \\
\hline $\mathrm{C} 4$ & 1.69 & 81 & 2.3 & 120 & 1.42 & 97 & 99.08 \\
\hline C7 & 1.70 & 81 & 2.14 & 129 & 1.42 & 97 & 99.15 \\
\hline C8 & 1.68 & 82 & 2.14 & 129 & 1.42 & 97 & 99.15 \\
\hline C9 & 1.69 & 81 & 2.14 & 129 & 1.42 & 97 & 99.16 \\
\hline
\end{tabular}

the refractive index of top layer. For $\lambda / 4-\lambda / 2-\lambda / 4$ triple-layer AR coatings, the reflectance at $\lambda$ will be zero if

$$
n_{\mathrm{top}}^{2} n_{\mathrm{s}}=n_{\mathrm{bot}}^{2}
$$

where $n_{\mathrm{s}}$ is the refractive index of substrate $\left(n_{\mathrm{s}}=1.52\right.$ for BK-7); $n_{\text {top }}, n_{\text {mid }}$ and $n_{\text {bot }}$ are the refractive indices of top layer, middle layer and bottom layer, respectively. The equation implies that the condition for zero reflection is independent of the refractive index of the middle layer. This is to be expected, since for a particular wavelength, a film with a half wavelength in optical thickness (or multiples thereof), which is the so-called absentee layer, does not change the performance at the central wavelength. But the over-all shape of the transmittance curve, however, will depend very strongly on $n_{\text {mid }}{ }^{21}$ (samples C2, C4 and C9). Here, we chose as-prepared $\mathrm{TiO}_{2}$ film, of which the refractive index is 2.14 (verified by ellipsometer) as the middle layer. As a film with a refractive index of 1.42 was selected as the top layer, an index of 1.75 would be required for the coating next to the glass to obtain zero reflectance at the central wavelength according to the equation (sample 3). However, for achieving a broad region of low-reflection rather than only at the central

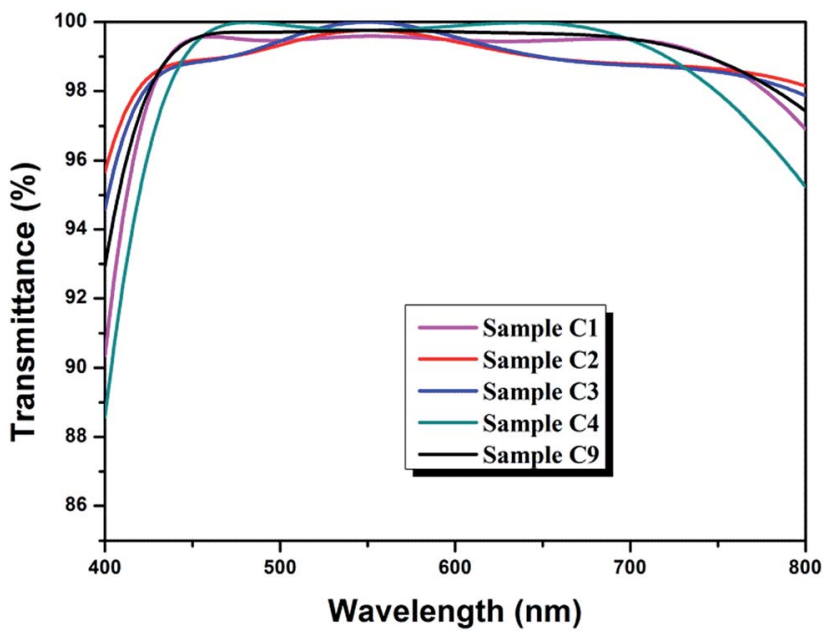

Fig. 1 Transmittance spectra of modeled triple-layer films picked from Table 1. wavelength, the $n_{\text {bot }}$ was adjusted slightly to deviate from the theoretical value (C9). Finally, the model C9 was selected for preparation broadband triple-layer films. The schematic illustration of C9 is shown in Fig. 2.

\section{Film materials for individual layers}

Synthesis of $\mathrm{SiO}_{2}$ and $\mathrm{TiO}_{2}$ by sol-gel process involves the hydrolysis of precursors and the formation of $\mathrm{Si}-\mathrm{O}-\mathrm{Si}$ or $\mathrm{Ti}-\mathrm{O}-\mathrm{Ti}$ by condensation reactions. The mechanistic aspects of hydrolysis, alcohol and water condensation reactions are widely available in literature. ${ }^{33,34}$ Under acid conditions, the hydrolysis of precursors is incomplete and the condensation reactions are tend to proceed at the end of the chain $(-\mathrm{OH}$ produced from hydrolysis) rather than at the middle (-OR). Hence the obtained polymers are linear chain network with a low degree of condensation. The films' chemical composition and degree of condensation were studied by FT-IR spectral analysis (Details in ESI†). The sols particles are composed mostly of small primary particles. The sizes of the acid-catalyzed $\mathrm{SiO}_{2}$ particles and acid-catalyzed $\mathrm{TiO}_{2}$ particles are $2.70 \mathrm{~nm}$ and $2.99 \mathrm{~nm}$, respectively (Fig. S4†).

The prepared $\mathrm{TiO}_{2}$ particles transformed into anatase phase with high crystallinity after calcination at $400{ }^{\circ} \mathrm{C}$, which was verified by the XRD pattern (Fig. S5 $\dagger$ ). The refractive indices of

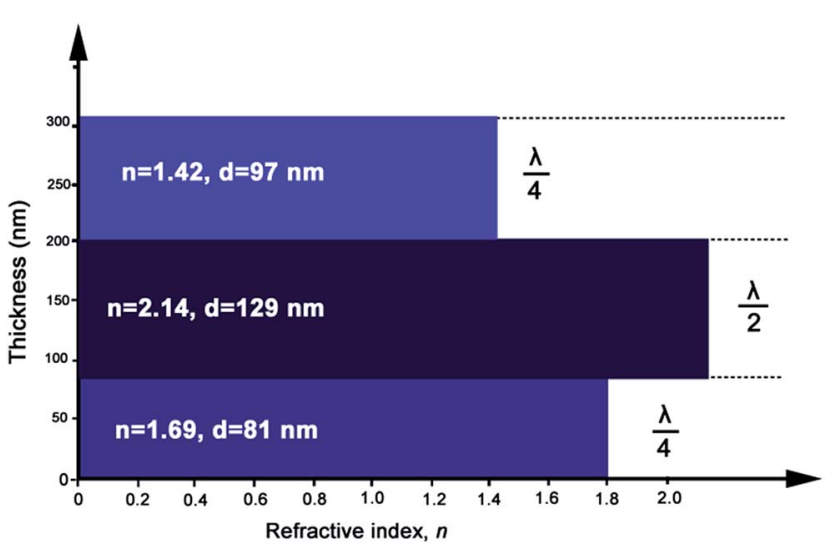

Fig. 2 Schematic illustration of the triple-layer broadband AR coating (C9). 
the calcined $\mathrm{TiO}_{2}$ film and the prepared acid-catalyzed $\mathrm{SiO}_{2}$ film, measured by ellipsometry, were 2.14 and 1.44 , respectively. Therefore, the combination of $\mathrm{TiO}_{2}$ and $\mathrm{SiO}_{2}$ sols can be used to achieve coatings with refractive indices ranging from 2.14 to 1.44. Fig. 3a shows the refractive indices of the prepared $\mathrm{TiO}_{2}-$ $\mathrm{SiO}_{2}$ composite coatings versus the $\mathrm{TiO}_{2}$ content (weight percent) in the sols. The refractive indices of the composite films markedly increased with an increase of $\mathrm{TiO}_{2}$ concentration. The thin film with refractive index of 1.69 for the bottom layer can be obtained with $\mathrm{TiO}_{2}$ content of $45 \mathrm{wt} \%$.

As to the top layer coating, an optical material with refractive index of 1.42 is required, so nanopores were introduced into the composites films to further decrease the refractive index. Considering that a certain amount of $\mathrm{TiO}_{2}$ is needed for effective photocatalysis, $30 \mathrm{wt} \% \mathrm{TiO}_{2}$ containing composite sols were used to fabricate porous films for top layer and F127 was used as pore generator. Fig. $3 \mathrm{~b}$ shows the change of refractive index of AR coatings as a function of the mass fraction of F127 in the corresponding sols. The refractive index initially decreased with an increase of F127 content, and reached asymptotically a minimum value of 1.36 . The film material with refractive index of 1.42 for the top layer can be achieved with F127 concentration of $3 \mathrm{wt} \%$.
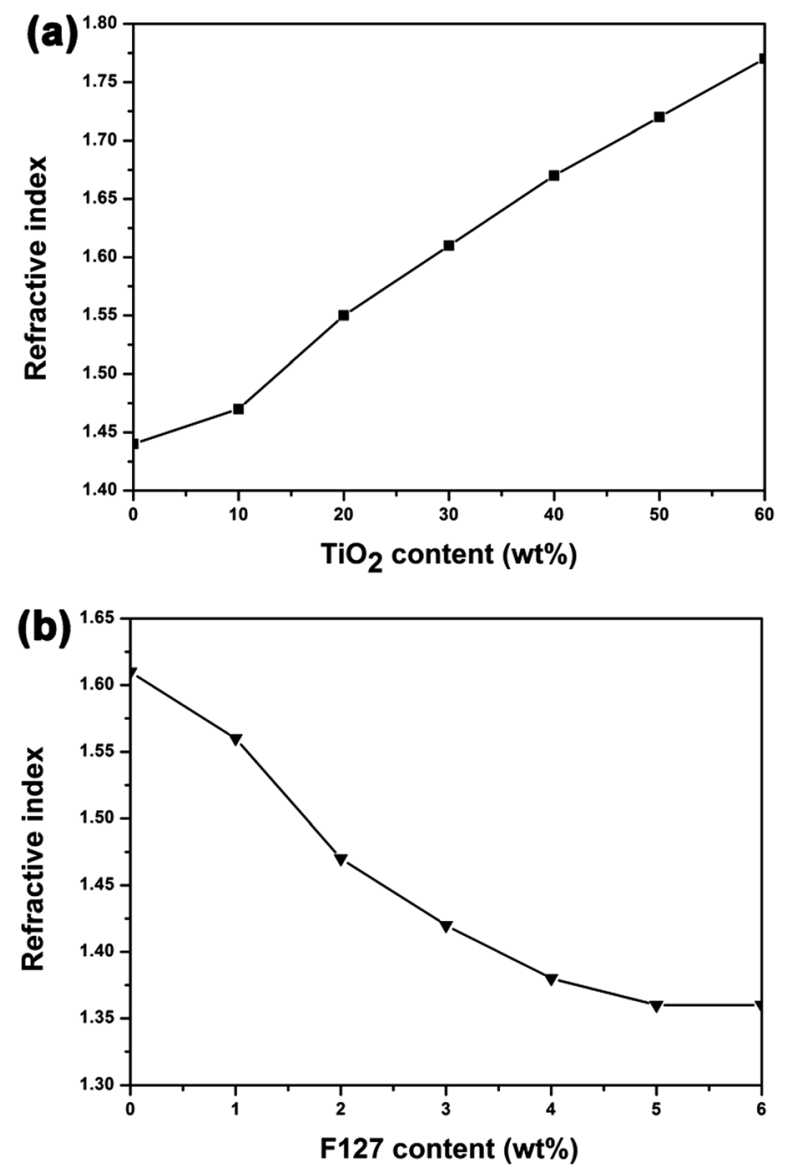

Fig. 3 (a) Changes of refractive index of composite films as a function of weight percent of titanium dioxide in composite sols. (b) Changes in refractive index of $30 \mathrm{wt} \% \mathrm{TiO}_{2}$ containing composite films as a function of mass fraction of F127 in sols.

\section{Optical performance of the triple-layer broadband AR coatings}

In sol-gel dip-coating process, film thickness is sensitive to room temperature and humidity, so the ambient condition should be well controlled. In this scenario, we kept the temperature at $30 \pm 1{ }^{\circ} \mathrm{C}$ and the humidity at $25 \pm 3 \%$. Before the preparation of the triple-layer films, each layer was deposited individually to obtain the desired thickness by varying the dip-coating speed (withdraw rate). After a series of experiments, the appropriate dip-coating speeds for individual layers were identified at $175 \mathrm{~mm} \mathrm{~min}^{-1}, 500 \mathrm{~mm} \mathrm{~min}^{-1}$ and $160 \mathrm{~mm} \mathrm{~min}^{-1}$ for bottom, middle and top layer, respectively. The triple-layer films were prepared by depositing the bottom layer, middle layer and top layer sequentially. The optical property of the triple-layer films are affected more easily by small variations in top layer's thickness than by similar variations in the other two layers' thickness, which means that the top layer's thickness should be accurately controlled.

The cross-sectional SEM image of a prepared trip-layer AR coating is shown in Fig. 4. The cross-section image shows distinguishable boundaries of top-middle and middle-bottom layers, and it could be seen that film thickness of each layer agreed well with the design values.

Fig. 5 shows the experimental and modeled transmittance spectra of triple-layer broadband AR coating as well as the measured transmittance spectrum of bare glass. The transmittances of the prepared triple-layer broadband AR coating were significantly enhanced compared to that of bare glass. The triple-layer film coated glass achieved consistent high transmittances at 500-700 $\mathrm{nm}$ and the average transmittance at that region was $99.4 \%$. At the entire visible region, the average transmittance was $98.7 \%$. Meanwhile, the experimental transmittance spectrum was in good agreement with our previous modeled spectrum (C9) over most of the spectral range. The deviation in the short-wavelength region was probably due to the dispersion of the refractive index in the wavelength region. ${ }^{35,36}$ In the theoretical simulation, it has been assumed that the refractive index of a film is constant, and the refractive index at $550 \mathrm{~nm}$ was adopted as the refractive index for the entire range of spectrum. However, in practical, the refractive

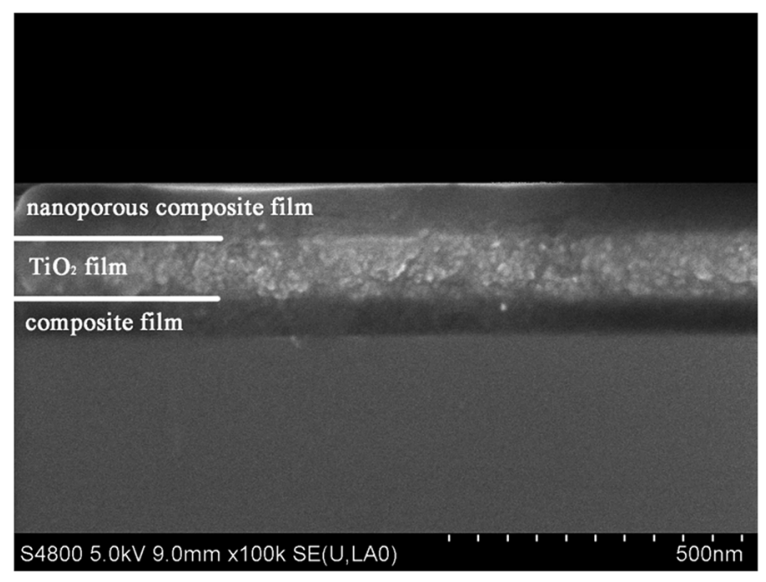

Fig. 4 Cross-section SEM image of the triple-layer antireflective film. 


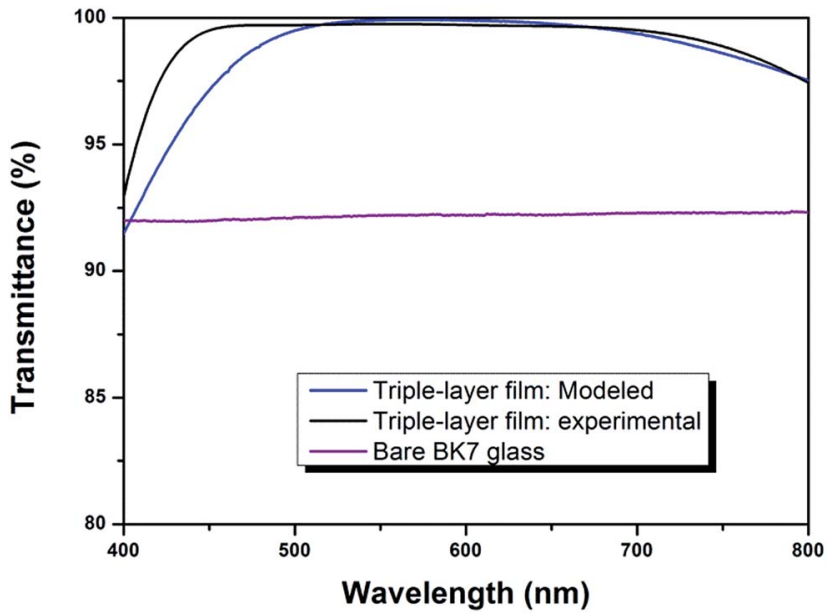

Fig. 5 Transmission spectra of modeled and experimental triple-layer AR coatings compared with that of bare BK7 glass.

indices of $\mathrm{TiO}_{2}$ and $\mathrm{SiO}_{2}$ increase with the decrease of wavelength, which leads to the differences between the experimental and designed transmittance spectra.

\section{Wettability of AR thin films}

The wettability of a surface is crucial for the self-cleaning function. A superhydrophilic surface favors the spread of water and the contaminants on the surface can be removed easily by rainwater. As to outdoor application, films are required to maintain superhydrophilicity for a long time, so the durability of the superhydrophilicity is a vital factor for practical application. Usually, the superhydrophilic property gradually weakens after storing for a few days or months under ambient conditions due to the deposition of dust or airborne volatile organic substances.

Here, we studied hydrophilicity changes of as-prepared $\mathrm{TiO}_{2}$ films, $\mathrm{TiO}_{2}-\mathrm{SiO}_{2}$ composite films $\left(30 \mathrm{wt} \% \mathrm{TiO}_{2}\right)$ and triple-layer films over time in the dark. Time-dependent variations of $0.5 \mathrm{~s}$ spreading and static water contact angles of the above films are shown in Fig. 6 and 7.

As shown in Fig. 6, all the freshly prepared $\mathrm{TiO}_{2}, \mathrm{TiO}_{2}-\mathrm{SiO}_{2}$ and nanoporous $\mathrm{SiO}_{2}-\mathrm{TiO}_{2}$ composite thin films showed intrinsic superhydrophilicity (below $5^{\circ}$ within $0.5 \mathrm{~s}$ ). Their water contact angle at a spreading time of $0.5 \mathrm{~s}$ were $1.8^{\circ}, 3.2^{\circ}$ and $2.1^{\circ}$ for $\mathrm{TiO}_{2}$ film, $\mathrm{SiO}_{2}-\mathrm{TiO}_{2}$ composite film and triple-layer film, respectively. After storing for 10 days, $\mathrm{TiO}_{2}$ film first lost its superhydrophilicity. The WCA of the composite film and the triple-layer film increased comparative slow and the superhydrophilicity of the triple-layer film could be sustained for a month. The static WCA of these films (Fig. 7) exhibited a similar rising tendency. What is worth mentioning is that the static WCA of the thriple-layer film was still nearly $5^{\circ}$ after storing in the dark for two months, showing a durability of hydrophilic property. Meanwhile, the triple-layer films also found to exhibit excellent antifogging behavior (Fig. S6†).

All these films showed excellent superhydrophilic property without UV illumination, especially the triple-layer film. Such

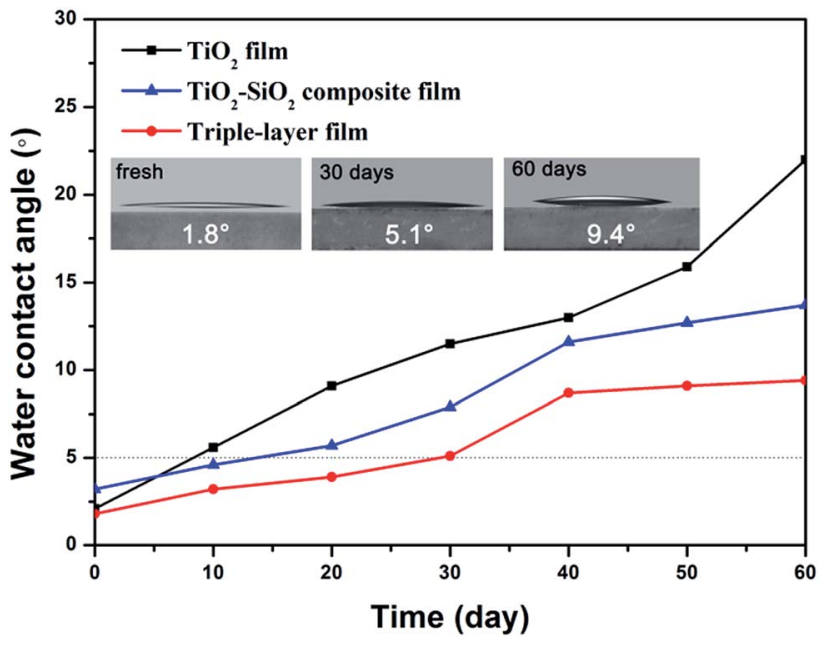

Fig. 6 Time-dependent variations of $0.5 \mathrm{~s}$ spreading water contact angle of $\mathrm{TiO}_{2}, \mathrm{TiO}_{2}-\mathrm{SiO}_{2}$ and triple-layer films. The insets are $0.5 \mathrm{~s}$ spreading water contact angle images of the triple-layer film for 0 day, 30 days and 60 days.

excellent wettability can be explained by films' chemical composition and microstructure. The $\mathrm{TiO}_{2}$ and $\mathrm{SiO}_{2}$ coatings fabricated by sol-gel method can exhibit intrinsic hydrophilicity through high temperature calcination due to the disappearance of hydrophobic $-\mathrm{OR}^{37}$ and high concentration of surface hydroxyl groups (Fig. S1†). ${ }^{38}$

Meanwhile, surface roughness and porosity also have important effects on surface wettability. ${ }^{39,40}$ The relationship between films' WCA and surface roughness can be explained by Wenzel's eqn (1): $:^{11,42}$

$$
\cos \theta_{\mathrm{w}}=r \cos \theta
$$

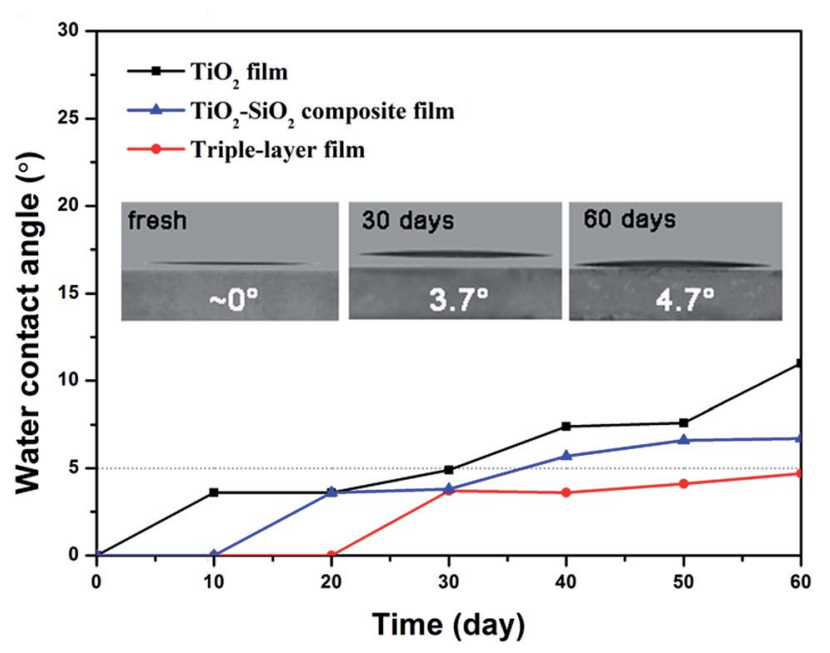

Fig. 7 Time-dependent variations of static water contact angle of $\mathrm{TiO}_{2}, \mathrm{TiO}_{2}-\mathrm{SiO}_{2}$ and triple-layer films. The insets are static water contact angle images of the triple-layer film for 0 day, 30 days and 60 days. 
where $\theta_{\mathrm{w}}$ is the contact angle on a rough surface, $\theta$ is the Young's contact angle on a similar smooth surface, and $r$ is the surface roughness factor, defined as the ratio of the actual surface area to the projected surface area (for a perfectly smooth surface: $r=1$, and for a rough surface: $r>1$ ). From this equation, we can conclude that apparent water contact angle $\theta_{\mathrm{w}}$ for a rough surface is lowered from its intrinsic contact angle $\theta$ by the roughness factor, if $\theta$ is smaller than $90^{\circ}$. AFM patterns of the surface morphologies for $\mathrm{TiO}_{2}$ film, $\mathrm{TiO}_{2}-\mathrm{SiO}_{2}$ composite film (30 wt $\left.\% \mathrm{TiO}_{2}\right)$ and triple layer film are shown under the same scale in Fig. 8. The surface of $\mathrm{TiO}_{2}$ film was very smooth; the root-mean-square (RMS) roughness $\left(R_{\mathrm{q}}\right)$ value was just $0.33 \mathrm{~nm}$. In contrast, the $\mathrm{TiO}_{2}-\mathrm{SiO}_{2}$ composite film and triplelayer film showed a rough surface with increased $R_{\mathrm{q}}$ values of $3.25 \mathrm{~nm}$ and $8.57 \mathrm{~nm}$, respectively. With the $R_{\mathrm{q}}$ value increased, the hill-to-valley surface morphology was gradually visible and such surface morphology obviously increases the surface area and the roughness factor $r$ in eqn (1). So the composite film and the triple layer film which own a rougher surface than the $\mathrm{TiO}_{2}$ film can obtain a lower WCA. Additionally, these $R_{\mathrm{q}}$ values are small enough not to cause any intense surface light scattering as long as wavelengths longer than $200 \mathrm{~nm}$ are concerned. ${ }^{43}$

The triple-layer film exhibited a better hydrophilic property than the composite film. This result may be attributed to the nano-porous structure of the triple-layer film's top layer, because the porous structure could generate a capillary force that attracts water into the pores and leads to a low contact angle. ${ }^{26,28}$

\section{Photocatalytic activities of the AR films}

Anatase $\mathrm{TiO}_{2}$ is a semiconductor with a large bandgap $\left(E_{\mathrm{g}}=3.2\right.$ $\mathrm{eV})$. Upon excitation by light of appropriate wavelength $(\lambda<385$ $\mathrm{nm}), \mathrm{TiO}_{2}$ can generate electron-hole pairs. The redox potential for photo-generated holes is $+2.53 \mathrm{~V}$, which can produce hydroxyl radicals $\left(\mathrm{OH}^{*}\right)$. The redox potential for conduction band electrons is $0.52 \mathrm{~V}$, which is enough to reduce oxygen to superoxide $\left(\mathrm{O}_{2}{ }^{-\cdot}\right)$, or to hydrogen peroxide $\left(\mathrm{H}_{2} \mathrm{O}_{2}\right) \cdot{ }^{44}$ Organic substances can be oxidized by the photo-generated holes on the valence band of $\mathrm{TiO}_{2}$ or by the active oxygen species. ${ }^{27,39,45}$ Previous research have shown that many liquid and solid organic compounds (alkanes, alcohols, ketones, carboxylic acids, etc.) can be oxidized into $\mathrm{CO}_{2}, \mathrm{H}_{2} \mathrm{O}, \mathrm{NO}_{3}{ }^{-}$or other simple basic products. ${ }^{46,47}$
To evaluate the photocatalytic activity of the prepared triplelayer films, HDTMS were employed to simulate organic contaminant in ambient environment. Silane molecules can react with the hydroxyls on the surface of $\mathrm{TiO}_{2}$ and $\mathrm{SiO}_{2}$, which has been well studied by Fadeev et $a .^{48,49}$ So after HDTMS modification, the alkyl chains of HDTMS molecules replace the hydroxyl and the films become hydrophobic. Illuminated by UV light, the alkyl chains can be decomposed gradually by $\mathrm{TiO}_{2}$, and the films again become hydrophilic. Thus, it is possible to evaluate the photocatalytic activity of the films by monitoring the change of water contact angle on the HDTMS modified surface during UV-irradiation. Fig. 9 shows the evolution of the water contact angle on HDTMS modified films including $\mathrm{TiO}_{2}$ film, $\mathrm{SiO}_{2}$ film, $\mathrm{SiO}_{2}-\mathrm{TiO}_{2}$ composite film (30 wt\% $\left.\mathrm{TiO}_{2}\right)$ and triple-layer film under UV illumination.

On $\mathrm{TiO}_{2}$ surfaces, the organic substances can be oxidized by the photo-generated holes on the valence band of $\mathrm{TiO}_{2}$ or by the active oxygen species. The active oxygen species can diffuse in the air phase, although diffusion rate is slow, and oxide the organic substance far from the locus of their formation. ${ }^{\mathbf{5 0 , 5 1}}$ As to the $\mathrm{TiO}_{2}-\mathrm{SiO}_{2}$ composite films, the HDTMS molecules on $\mathrm{TiO}_{2}$ particles can be decomposed directly, but the HDTMS molecules on $\mathrm{SiO}_{2}$ particles were decomposed through

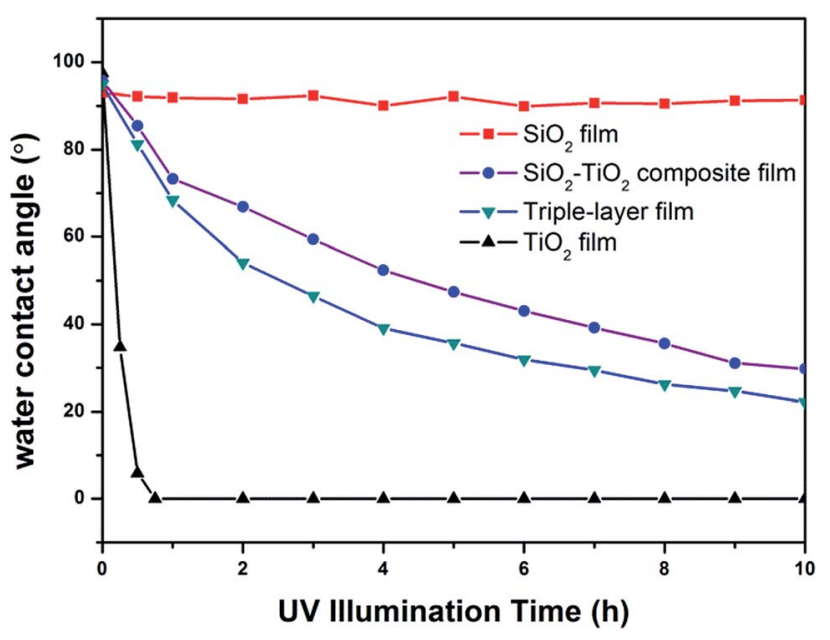

Fig. 9 Water contact angle changes of HDTMS-modified films including $\mathrm{SiO}_{2}$ film, $\mathrm{TiO}_{2}$ film $\mathrm{SiO}_{2}-\mathrm{TiO}_{2}$ composite film (30 wt\% $\mathrm{TiO}_{2}$ ) and triple-layer film under UV illumination.
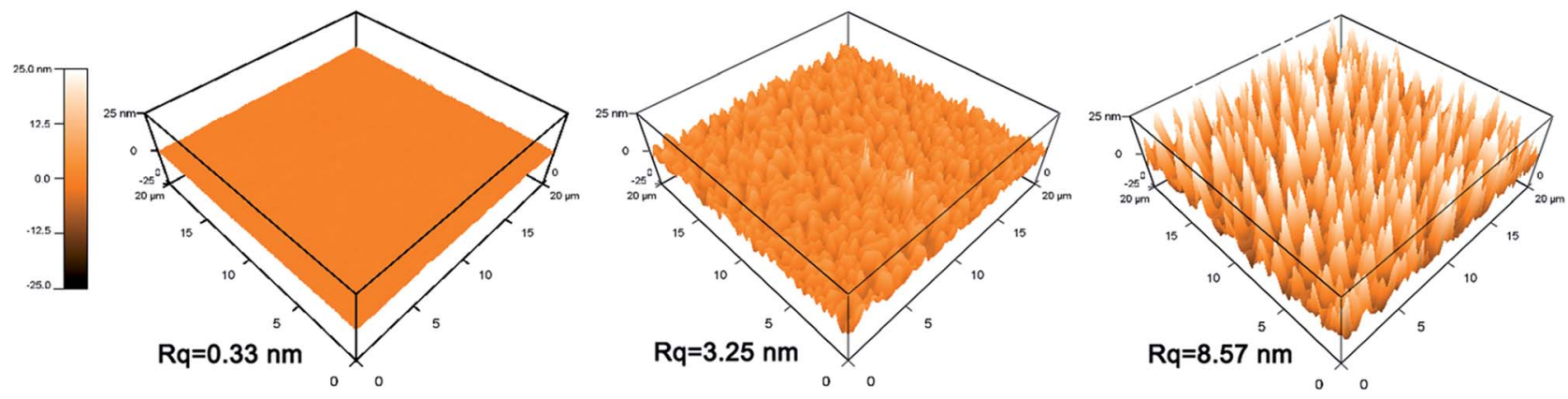

Fig. 8 Surface topography of films by AFM: (a) $\mathrm{TiO}_{2}$ film, (b) $\mathrm{TiO}_{2}-\mathrm{SiO}_{2}$ composite film (30 wt\% $\mathrm{TiO}_{2}$ ), (c) triple-layer film. 
diffusion of photogenerated active oxygen species at a slower rate. Therefore, it is reasonable that the $\mathrm{SiO}_{2}-\mathrm{TiO}_{2}$ composite film and the triple-layer film, which possess a low coverage rate of $\mathrm{TiO}_{2}$ particles on the surface, showed a slower rate of photocatalytic oxidation. Additionally, minor differences were observed between the photodegradation rate of the composite film and the triple-layer film, and such differences may be attributed to the triple-layer film's porosity structure, which is beneficial to a rapid diffusion of reactants (active oxygen species) and products $\left(\mathrm{CO}_{2}\right.$ and $\left.\mathrm{H}_{2} \mathrm{O}\right)$ during UV illumination, and thus enhance photocatalytic activity. ${ }^{31,52}$

HDTMS molecules were decomposed under UV irradiation gradually, demonstrating films' self-cleaning potential. Provided the rate of photocatalysis is higher than the rate of contamination, the coating can keep its surface free from organic contamination through UV illumination. And the photocatalysis combined with the durable superhydrophilicity provides the films with self-cleaning effect, which is vital for long-term outdoor use.

\section{Mechanical performance}

Considering the harsh natural condition and the frequent cleaning process during practical application, the AR coatings are required to be robust. In this study, to evaluate the mechanical strength of the triple-layer film, we measured the changes of transmittance before and after being rubbed with abrasion-resistance test equipment, as a slight damage of film's structure during the process of rubbing can lead to a noticeable decrease in transmittance. As shown in Fig. 10, AR performance of the triple layer coating remained almost intact, with only a $0.35 \%$ reduction of average transmittance in the region of 400-800 $\mathrm{nm}$, indicating that the triple-layer film has strong mechanical strength and good adhesion to substrate.

As to acid-catalyzed sol, the growth of clusters can be described as a RLCA (Reaction Limited Cluster-cluster Aggregation) model, ${ }^{53}$ resulting in a structure of linear chains, and the particle size are very small with many particle-particle

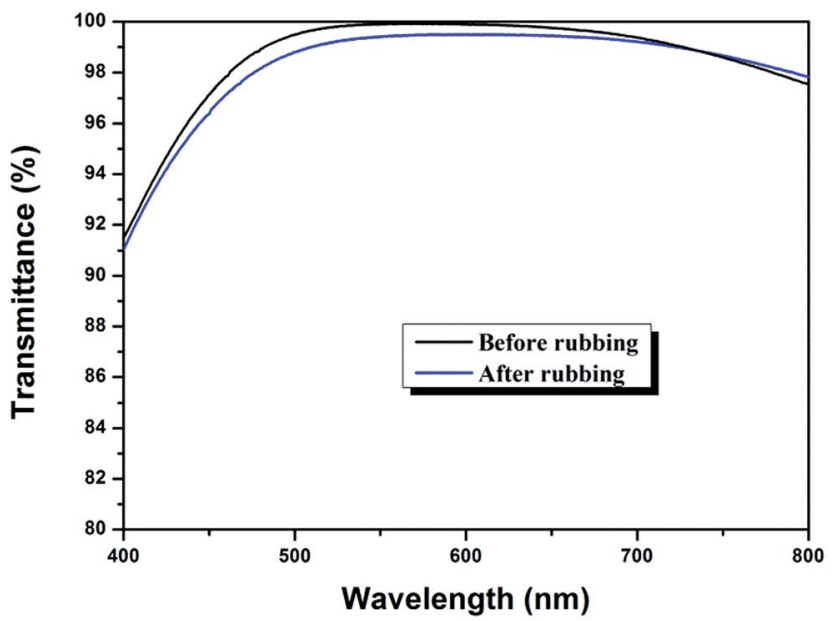

Fig. 10 Changes in transmittance of the triple-layer coating before and after abrasion. bondings, ${ }^{54}$ and thus the formed film tends to be dense and robust. Additionally, the sintering process of the coatings enables the formation of anatase- $\mathrm{TiO}_{2}$, which exhibits high hardness. Meanwhile, the sintering process can further improve coating strength and adhesion to glass substrates. ${ }^{5,56}$ Therefore, the triple-layer film, which adopted acid catalyzed coatings as film material, showed good mechanical property. The film material of the bottom layer used in this work was acid catalyzed silica-titania composite film, considered to be robust and have good adhesion to the substrate. However, as to the top layer, nanopores were introduced into the composite film and the porosity can influence the dense structure of the film, leading to a slight decrease of transmittance after the rubbing test. Nevertheless, this slight decrease was acceptable and the triple-layer films retained high transparency after rubbing test.

\section{Conclusion}

Triple-layer interference broadband AR coatings were designed and optimized with the aid of thin film design software TFCalc ${ }^{\mathrm{TM}}$, and the optimized broadband AR coating was successfully realized using sol-gel dip-coating method. The triple-layer film can afford BK-7 glass broadband AR property with a high $\mathrm{TiO}_{2}$ content of $30 \mathrm{wt} \%$ in the top layer. Substrates coated with the triple-layer films attained consistent high transmittances at 500-700 $\mathrm{nm}$ and the average transmittance at that region was $99.4 \%$. At the entire visible region, the average transmittance was $98.7 \%$. Nanoporous $\mathrm{TiO}_{2}-\mathrm{SiO}_{2}$ composite thin film was applied as the top layer, which endows the triplelayer film with intrinsic superhydrophilicity. And the superhydrophilicity can persist over a period of a month. This broadband AR film also exhibited photocatalytic activity to decompose organic compounds under UV light. The synergistic effect between superhydrophilicity and photocatalysis provided the films with self-cleaning property. The dense structure and particle-particle bondings of acid-catalyzed film material guarantee the mechanical stability of the triple-layer film, and the triple-layer films retained high transparency after rubbing test. Therefore, this triple-layer film with combined properties of broadband antireflection, durable superhydrophilicity, photocatalysis and mechanical robustness have potential to be applied in energy-related instrument and optical device.

\section{Acknowledgements}

The authors gratefully acknowledge the support from the Natural Science Foundation of China "Project J1103315" supported by NSFC.

\section{References}

1 G. Helsch and J. Deubener, Sol. Energy, 2012, 86, 831-836.

2 Q. Zhang, Y. Wei, W. Yang, H. Hui, X. Deng, J. Wang, Q. Xu and J. Shen, RSC Adv., 2015, 5, 4529-4536.

3 M. Mazur, D. Wojcieszak, D. Kaczmarek, J. Domaradzki, S. Song, D. Gibson, F. Placido, P. Mazur, M. Kalisz and A. Poniedzialek, Appl. Surf. Sci., 2016, 380, 165-171. 
4 T. Li, J. He, L. Yao and Z. Geng, J. Colloid Interface Sci., 2015, 444, 67-73.

5 T. Ren, Z. Geng, J. He, X. Zhang and J. He, J. Colloid Interface Sci., 2017, 486, 1-7.

6 J. W. Leem, J. S. Yu, Y. M. Song and Y. T. Lee, Sol. Energy Mater. Sol. Cells, 2011, 95, 669-676.

7 F. Galeotti, F. Trespidi, G. Timo and M. Pasini, ACS Appl. Mater. Interfaces, 2014, 6, 5827-5834.

8 W. K. Kuo, J. J. Hsu, C. K. Nien and H. H. Yu, ACS Appl. Mater. Interfaces, 2016, 8, 32021-32030.

9 Y.-Y. Chou, K.-T. Lee and Y.-C. Lee, Appl. Surf. Sci., 2016, 377, 81-85.

10 D.-S. Kim, S. Kwon, K. Lee and J.-H. Jang, Appl. Surf. Sci., 2015, 332, 716-719.

11 S. L. Diedenhofen, G. Grzela, E. Haverkamp, G. Bauhuis, J. Schermer and J. G. Rivas, Sol. Energy Mater. Sol. Cells, 2012, 101, 308-314.

12 W. H. Southwell, Opt. Lett., 1983, 8, 584-586.

13 J. Q. Xi, M. F. Schubert, J. K. Kim, E. F. Schubert, M. Chen, S.-Y. Lin, W. Liu and J. A. Smart, Nat. Photonics, 2007, 1, 176-179.

14 X. Yan, D. J. Poxson, J. Cho, R. E. Welser, A. K. Sood, J. K. Kim and E. F. Schubert, Adv. Funct. Mater., 2013, 23, 583-590.

15 D. Li, D. Wan, X. Zhu, Y. Wang, Z. Han, S. Han, Y. Shan and F. Huang, Sol. Energy Mater. Sol. Cells, 2014, 130, 505-512.

16 M. Faustini, L. Nicole, C. d. Boissière, P. Innocenzi, C. m. Sanchez and D. Grosso, Chem. Mater., 2010, 22, 4406-4413.

17 H. K. Raut, V. A. Ganesh, A. S. Nair and S. Ramakrishna, Energy Environ. Sci., 2011, 4, 3779-3804.

18 X.-X. Zhang, S. Cai, D. You, L.-H. Yan, H.-B. Lv, X.-D. Yuan and B. Jiang, Adv. Funct. Mater., 2013, 23, 4361-4365.

19 Y. Li, H. Lv, L. Ye, L. Yan, Y. Zhang, B. Xia, H. Yan and B. Jiang, RSC Adv., 2015, 5, 20365-20370.

20 J. Sun, X. Cui, C. Zhang, C. Zhang, R. Ding and Y. Xu, J. Mater. Chem. C, 2015, 3, 7187-7194.

21 L. B. Lockhart and P. King, J. Opt. Soc. Am., 1947, 37, 689694.

22 J. T. Cox, G. Hass and A. Thelen, J. Opt. Soc. Am., 1962, 52, 965-969.

23 L. Ye, Y. Zhang, X. Zhang, T. Hu, R. Ji, B. Ding and B. Jiang, Sol. Energy Mater. Sol. Cells, 2013, 111, 160-164.

24 S. Guldin, P. Kohn, M. Stefik, J. Song, G. Divitini, F. Ecarla, C. Ducati, U. Wiesner and U. Steiner, Nano Lett., 2013, 13, 5329-5335.

25 Y. Wang, J. Wu, H. Wang and R. Chen, Sol. Energy, 2015, 122, 763-772.

26 L. Yao, J. He, Z. Geng and T. Ren, Nanoscale, 2015, 7, 1312513134.

27 X.-T. Zhang, O. Sato, M. Taguchi, Y. Einaga, T. Murakami and A. Fujishima, Chem. Mater., 2005, 17, 696-700.
28 K. Nakata, M. Sakai, T. Ochiai, T. Murakami, K. Takagi and A. Fujishima, Langmuir, 2011, 27, 3275-3278.

29 S. Li, J. Huang, Z. Chen, G. Chen and Y. Lai, J. Mater. Chem. A, 2017, 5, 31-55.

30 R. Prado, G. Beobide, A. Marcaide, J. Goikoetxea and A. Aranzabe, Sol. Energy Mater. Sol. Cells, 2010, 94, 10811088.

31 L. Yao and J. He, J. Mater. Chem. A, 2014, 2, 6994-7003.

32 Q. Mao, D. Zeng, K. Xu and C. Xie, RSC Adv., 2014, 4, 5810158107.

33 J. Livage, M. Henry and C. Sanchez, Prog. Solid State Chem., 1988, 18, 259-341.

34 C. J. Brinker, J. Non-Cryst. Solids, 1988, 100, 31-50.

35 D. Bouhafs, A. Moussi, A. Chikouche and J. M. Ruiz, Sol. Energy Mater. Sol. Cells, 1998, 52, 79-93.

36 S. Lien, D. Wuu, W. Yeh and J. Liu, Sol. Energy Mater. Sol. Cells, 2006, 90, 2710-2719.

37 L. Ye, Y. Zhang, C. Song, Y. Li and B. Jiang, Mater. Lett., 2017, 188, 316-318.

38 X. Li and J. He, ACS Appl. Mater. Interfaces, 2013, 5, 52825290.

39 Z. Liu, X. Zhang, T. Murakami and A. Fujishima, Sol. Energy Mater. Sol. Cells, 2008, 92, 1434-1438.

40 L. Yao and J. He, Prog. Mater. Sci., 2014, 61, 94-143.

41 R. N. Wenzel, Ind. Eng. Chem., 1936, 28, 988-994.

42 Q. David, Rep. Prog. Phys., 2005, 68, 2495.

43 Y. Xu, W. H. Fan, Z. H. Li, D. Wu and Y. H. Sun, Appl. Opt., 2003, 42, 108-112.

44 A. Fujishima and X. Zhang, C. R. Chim., 2006, 9, 750-760.

45 A. Fujishima, X. Zhang and D. Tryk, Surf. Sci. Rep., 2008, 63, 515-582.

46 Y. Ohko, K. Hashimoto and A. Fujishima, J. Phys. Chem. A, 1997, 101, 8057-8062.

47 J. Lee, H. Park and W. Choi, Environ. Sci. Technol., 2002, 36, 5462-5468.

48 A. Y. Fadeev and T. J. McCarthy, Langmuir, 1999, 15, 37593766.

49 R. Helmy and A. Y. Fadeev, Langmuir, 2002, 18, 8924-8928.

50 H. Haick and Y. Paz, J. Phys. Chem. B, 2001, 105, 3045-3051.

51 T. Tatsuma, S.-i. Tachibana and A. Fujishima, J. Phys. Chem. $B, 2001,105,6987-6992$.

52 L. Ren, Y. Li, J. Hou, X. Zhao and C. Pan, ACS Appl. Mater. Interfaces, 2014, 6, 1608-1615.

53 M. J. Vold, J. Colloid Sci., 1963, 18, 684-695.

54 A. Vincent, S. Babu, E. Brinley, A. Karakoti, S. Deshpande and S. Seal, J. Phys. Chem. C, 2007, 111, 8291-8298.

55 B. G. Prevo, Y. Hwang and O. D. Velev, Chem. Mater., 2005, 17, 3642-3651.

56 D. Lee, M. F. Rubner and R. E. Cohen, Nano Lett., 2006, 6, 2305-2312. 